\title{
LITERATURA BRASILEIRA EM CURSO, UM LIVRO DE COLECIONADORES
}

Maria Helena Werneck

(UNIRIO/CNPq)

\section{RESUMO}

O artigo analisa o projeto do livro Literatura Brasileira em Curso, de autoria dos Professores Dirce Côrtes Riedel, Carlos Nascimento e Tereza Barbieri (Terezinha de Castro). Tomando como referência conceitos de Walter Benjamin como os de coleção, biblioteca, miniatura, infância e montagem de tempos, descreve a arquitetura inovadora da antologia didática, percebendo as diferentes configurações de álbuns textuais em torno de temas. Observam-se procedimentos que favorecem múltiplas experiências da leitura, indicando modos contemporâneos de perceber o estado de emergência da literatura brasileira, inovando a prática de visadas historicistas de classificação e ordenação do texto.

PALAVRAS-CHAVE: Literatura brasileira; coleção; leitura.

O convite de Walter Benjamin ao leitor é irresistível - transferir-se com ele para a desordem de caixotes abertos, de onde emergem livros, e deixar-se envolver em "maré de água viva de recordações", que a arte de colecionar propicia (Benjamin, 1987: 227). Diante do mundo dos objetos, a mão do colecionador que, muito antes, retirara um livro do "mostruário de vidro", onde estava depositado à espera de eleição, indica que há um novo movimento em curso, o encontro do objeto com o sujeito e com a sua própria coleção.

Com o pensamento que avança, suplantando o dique das lembranças, surgem outras ideias. Uma delas é a do círculo mágico a circundar a compra do livro ambicionado. A imagem inicial do círculo se transforma na da enciclopédia mágica, pronta a indicar qual teria sido o destino do livro, desde a época e o local, onde se configurara a materialidade de sua 
criação, até o conhecimento de seu dono anterior. Outra bela ideia é a de renascimento e renovação, que ocorrem quando um livro, especialmente se bem antigo, passa para novas mãos. Benjamin remete à imagem dos modos de apropriação infantil, inerentes ao brincar das crianças quando pintam objetos, recortam figuras e experimentam a decalcomania. Tocar é anterior a nomear, e no decorrer dessa passagem, renova-se o mundo velho.

A renovação, que é inerente ao ato de comprar do colecionador, não está presente na expectativa do estudante ao adquirir um livro texto para as aulas, do homem em busca de um presente para uma mulher, daquele que deseja apenas um livro para passar o tempo gasto num meio de transporte. Entre o acaso e a determinação, o colecionador atravessa cidades tanto quanto consulta catálogos para fazer encomendas. Em todos os casos, a aquisição de um livro e a constituição de uma biblioteca inclui o inescrutável e o inconfundível (Benjamin, 1987: 231) e pode não depender exatamente nem do dinheiro nem da expertise.

Ao lado dessa incursão no universo do colecionador, Benjamin volta ao colecionismo quando, em Infância Berlinense, aborda o comércio de selos. O belo texto exalta o miniaturismo e a montagem de imagens em ínfimas dimensões: "Selos estão eriçados de cifrazinhas, letras diminutas, folhinhas e olhinhos. São tecidos celulares gráficos. Isso tudo fervilha entremeado e, como os animais inferiores; mesmo despedaçado, continua a viver." O que sobrevive e se sobrepõe à matéria morta é a colagem de partículas que resultam em "imagens tão eficazes" da dialética da vida e da decomposição.

As miniaturas dos selos criam também imagens dialéticas de espaços e tempos. Os distantes países e mares "são apenas as províncias". Alguns "tem o aspecto daquelas primeiras fotos, da quais, dentro das molduras laqueadas de preto, parentes que nunca conhecemos olham para nós" (Benjamin, 1987: 58). As crianças, ainda uma vez, no pensamento de Benjamin, além de serem hábeis renovadoras, são capazes de ir, através do mínimo, ao território distante, como a praia na Libéria, e também ao longínguo, como o velejar de Vasco da Gama. Aproveitando o poder da miniatura diante de seus olhos, os pequenos selos transformam o detalhe insignificante em lance no jogo de imaginação (Missac, 1998: 82), tornando a infância uma eterna guardiã daquilo que merece sobreviver (Agamben, 2005: 157).

Desta longa epígrafe colhem-se imagens fortes para pensar o pro- 
jeto de Literatura Brasileira em Curso, livro de textos lançado em 1968 com a autoria compartilhada por quatro professores experientes: Dirce Riedel, Carlos Nascimento, Ivo Barbieri e Terezinha Castro, que teve seguidas edições até 1971. Esses colecionadores, ao modo do pensador alemão, abrem e desmontam suas bibliotecas, criando contiguidades originais entre textos que extraem de obras da literatura brasileira do século XVII à segunda metade do século XX.

Aquela inesperada zona que rompe, no dizer de Benjamin, o "suave tédio da ordem", se instala para ganhar ordenamentos "em curso", abertos, portanto, a arranjos que vão além da proposta de uma antologia na qual predominam unidades textuais postas em molduras de épocas. Se os grandes colecionadores distinguem-se pela originalidade na de objetos, muitos outros deixam-se guiar pelos próprios objetos (Benjamin, 2013: 163), a diretriz colecionista praticada pelos autores procura equilíbrio de orientações e cria álbuns textuais em torno de temas que se sucedem, formando seis grandes conjuntos identificados por algarismos romanos: I - Povo, Trabalho, Jogo; Protesto; II - Isolamento, Fuga, Busca; III Amor, Delírio, Liberdade; IV - Bichos, Tipos, Heróis, Mitos; V - Espaço, Tempo. Exílio; VI - Coisas, Retratos, Arte. Tira-se partido da miniaturização, quando se separa a página de romances, o trecho de um capítulo, um conto ou um poema da inteireza da obra, deslocando-os do livro em que está inserido, seja ele uma obra de eleição antiga, seja exemplar que recém ocupa novo lugar na coleção que desempacotam - J.J.Veiga, Autran Dourado, Dalton Trevisan. Em todos os casos, invoca-se a autoridade de quebrar unidades fortes das obras em que se estampavam inicialmente. Este ato de descolar textos de livros para valorizar a miniatura e colocá-la ao lado de outra, se por um lado cria intervalos temporais muito alongados entre as obras, por outro permite que se mergulhe nas dinâmicas temporais internas a cada texto.

Nesse sentido é interessante perceber o primeiro álbum textual, articulado em torno do tema Povo. O que se encena em fragmentos narrativos de romances, em contos curtos e em poemas são a procissão que surge na rua, os percursos de penitente, o ritual da macumba em torno da saudação dos santos e dos pedidos de benefícios concretos dos participantes. Espera-se pelo início de um casamento numa casa do interior, defronta-se com o tumulto num bonde e incorpora-se o leitor ao gozo presumido de uma partida de futebol prestes a ser iniciada. Preserva-se, assim, uma experiência de temporalidade ficcional que explora a inserção 
na cultura cotidiana do povo. De alguma forma, se abranda a continuidade da periodização histórica que vai de Manuel Antônio de Almeida a Mário de Andrade, de Drummond a Armando Nogueira, o cronista de futebol. Prefere-se, no primeiro álbum, que o leitor mergulhe no tempo, em sua densidade forjada por agentes anônimos, verdadeiros figurantes como nos filmes de Eisenstein ou Pasolini.

Outra consequência da miniaturização é perceptível no álbum Protesto, no qual múltiplas variações de tom e ritmo se oferecem às experiências de leitura através do confronto das pequenas dimensões textuais. Gregório de Matos parte para o degredo e é a instância da despedida que incrementa a visão da subordinação colonial. A verve de Tomás Antônio Gonzaga contra a distribuição de privilégios em confronto surpreende ao lado da voz de Castro Alves em exortação ao Poder divino e sua indiferença em relação à escravidão. Estas vozes altas se alternam para tons mais baixos na narrativa surpreendente da malhação de Judas no sertão feita por Euclides da Cunha e no desencanto do Policarpo em relação às quimeras a que devotara a vida. A canção popular, de Mário, ou as imagens oníricas, de Murilo, são interrompidas pelas paisagens duramente belas de Cabral, em "Cão sem plumas", para, inesperadamente, fazer vizinhança com um fragmento da prosa de Autran Dourado, em A Barca dos Homens, em que o personagem Frei Miguel tenta defender o louco Fortunato das garras da polícia. A contiguidade temática, neste caso, não unifica mas abre fendas e cria a experiência de diferentes dimensões e gradações do sentimento, manifestas no desacordo, na denúncia, na insatisfação, na revolta. Não importa aqui determinar exatamente a margem contextual do objeto da revolta, mas sim perceber as linguagens através das quais o ímpeto do não toma forma e se torna gesto.

A experimentação da diversidade rítmica enunciativa, tal como praticada no álbum anterior, pode dar lugar a estudos da figuração, que extrapolam, em consequência da fragmentação do recorte realizado, o conceito de personagens, a depender da magnitude extensa da narrativa. Cortes e montagem compõem, portanto, tábuas de imagens de animais e de homens. O título do álbum - Bichos, Tipos, Mitos, embora tenha a sonoridade de um verso, revela uma intenção de captar o instante do desenho feito à mão. Ou mesmo a tomada de forma da linha, na vertigem mínima de um desenho animado, tal como no conto breve de Mário Quintana, em que o limite entre a vida e a morte do peixinho está na mão e na imaginação de um pescador. A assinatura dos autores desenhistas é 
evidente. O que eles captam são detalhes que pungem, ou os punctuns de Roland Barthes. Depois do peixinho do poeta gaúcho seguem a Galinha de Clarice, a cadela Pingo-de-ouro do Miguilim, os cavalos abatidos e chorados pelos vaqueiros, ambos em obras de Guimarães Rosa. Os urubus de Mário Palmério, alvos inalcançáveis dos fazendeiros mineiros se encontram com o urubu de Cabral, funcionário da seca. Para os tipos, que nada têm daquelas identidades fixas imediatamente reconhecíveis, os processos de figuração podem, no entanto, saltar do instante do gesto para o ponto da observação mais completa que tenta apreender ora a individualidade ora a capacidade de representação coletiva e formação do imaginário. Revelam-se, assim, nomes que são imagens (Vidinha, Emília, Rita Baiana, Aristarco, Inácio, Cabo Machado, Paulo Honório, Bibiana, Gabriela, Biela). No entanto, de modo diverso do caso dos bichos, em que se visualiza a mão dos seus autores, os tipos ganham estatuto pelo pertencimento à memória da literatura.

A relação entre geografias e escrita se apresenta na Parte V, cujos álbuns se denominam Espaço, Tempo, Exílio. Há nos textos selecionados a pregnância do vivido na paisagem. O espaço é tomado pela experiência que o torna miniatura a ser escrutinada pela sensação e pela memória, não pelo traço sinuoso no mapa amarelecido. É assim que o narrador de $O s$ Sertões descreve o encontro com os corpos de um soldado e de cavalos mortos num assalto das forças republicanas a Canudos, todos humanos e animais já mumificados pelo abandono no relento. Se por um lado o território é museu da passagem brutal dos homens, por outro é paisagem comandada inteiramente pelo poder da natureza que produz "fenômenos óticos bizarros" para os olhos do forasteiro. Mas, em sentido inverso, o olho humano pode captar mecânicamente a natureza animada, meio vegetal, meio animal. Como nos cliques oswaldianos e na sensorialização corporal do fluido da floresta de Raul Bopp. Já que os álbuns nem sempre primam pelo encantamento do leitor; ao contrário, apostam na surpresa e muitas vezes em certo desconforto, a próxima parada, assinada por Monteiro Lobato, é uma cidade perdida ao lado do leito da estrada de ferro, na qual as "pedras que os homens pisavam lhes transmitiam mais dureza na solidão da Cordilheira".

Os últimos álbuns, da parte VI - Coisas, Retratos, Arte, levam o leitor para a experiência da percepção poética dos objetos banais em na intimidade de Álvares de Azevedo, na fábula machadiana de "Cantiga de Esponsais", no travalíngua de Cecília Meirelles, na mala mágica de coi- 
sas e histórias do mascate Xixi Piriá que anda pelos sertões menos áridos de Mário Palmério, na curiosidade colecionadora que rende ao menino, obrigado muito prematuramente ao trabalho, boa diversão ao explorar as prateleiras da venda de seu patrão e encantar-se por uma simples fivela de latão. Lá está, também, "O relógio", ganhando força de bestiário pela palavra de João Cabral. O álbum ganha força de almanaque.

Ao optar por coletar no último álbum, "Arte", a contraface do que foi ofertado anteriormente, apresentando o urdimento das cenas narrativa e poética pela própria enunciação de alguns dos autores que assinam textos selecionados (Cantiga de Esponsais, de Machado de Assis, O Lutador e A mão, de Drummond, Bem Aventurados, de Quintana, Psicologia da Criação, de Cabral, entre outros), o livro insere o leitor na instância do pensamento sobre as políticas da criação poética e sobre a relação entre arte e subjetividade. Os textos flagram artistas em instantes de enfrentamento com a força plástica das linguagens artísticas, que incorpora lembranças e metamorfoses de imagens, de frases sonoras, de palavras. $\mathrm{O}$ enfoque no trato com a materialidade do texto, da pedra, da cor, da nota musical, cria uma faixa final do livro dedicada ao embate e ao experimento da arte, reforçando a percepção segundo a qual a obra literária abre-se a múltiplas historicidades.

Dessa forma, a perspectiva dada pela denominação "em curso" do título do livro distancia-se de uma visada historicista na apresentação e no ensino da literatura brasileira, procurando soltar os textos de sua inscrição obrigatória numa continuidade baseada em condicionamentos de ordem histórico-social ou de ordem histórico estilística. Embora sejam possíveis gestos de reconstrução de séries que retirem os textos dos álbuns temáticos e os unam por autoria e por conjuntos de época, de modo a localizá-los numa linearidade organizada retilinearmente, a visão colecionista e miniaturista que estrutura o livro resiste a esse propósito.

A epígrafe de Auerbach, escolhida pelos autores para abrir o volume, indica a atenção no teor de historicidade interna da obra, na medida em que, para o filólogo alemão, a história adentra a obra de arte literária, conformando-a como obra, forma e "visão" (Waizbort, 2004: 69). No entanto, o projeto da edição resulta em certo deslocamento em relação à inspiração auerbachiana. Pensando como a valorização do instante do texto (passagens de Hamlet, Fedra ou Fausto) torna-se condição de acesso ao autor, a organização do volume, observa, além das relações históricas interiores ao texto, os modos operativos de leitura, afinal se trata de mate- 
rial a ser manipulado por professores e alunos. A consequência é que, no processo de uso dos álbuns temáticos, acaba-se privilegiando "a imagem paradoxal de um 'estado de história', cujo evento fundamental está sempre em curso e cuja meta não se encontra distante no futuro, mas está já, sempre presente", como define Agamben ao explicar a crítica benjaminiana ao tempo contínuo qualificado (Agamben, 2005:124). O presente é o tempo-agora e, portanto, os álbuns temáticos são dotados da capacidade de produzir o "estado de emergência" da arte da literatura.

Ao retomar, agora, Literatura Brasileira em Curso, que adotei em aulas do ensino médio e universitário, décadas atrás, encontro, na formulação do livro, um conceito de tempo que se aproxima da forma do prazer, tal como já percebido em formulação aristotélica, como algo que "diversamente do movimento, não se desenrola em um espaço de tempo, mas é a cada instante um quê de inteiro e de completo" (Agamben, 2005: 127). Ficam definitivamente para trás os exercícios de identificação de autor e estilo, em prol de uma aproximação mais lúdica e mais fresca do conjunto de textos, aberta a novos impulsos não só para reforçar a dimensão in progress do projeto, mas também para ampliar os álbuns ou criar novas unidades temáticas, abarcando a produção da literatura brasileira nas últimas quatro décadas. Na passagem dos 1960 aos 1970, anos nos quais se forjaram, no Brasil e no mundo, experiências fundamentais de revolução e de luta contra o conservadorismo, na política, nas artes e na cultura, o livro, com capa de Aluisio Carvão adotava design gráfico para abrigar imagens de cinema, de fotografia e artes plásticas, propiciando múltiplos diálogos interartísticos. Fazer um chamado à inclusão de bibliotecas de novos colecionadores neste projeto seria, nos dias atuais, manter a ideia de uma história da literatura que incorpora a experiência livre do tempo.

\section{LITERATURA BRASILEIRA EM CURSO: A BOOK FOR COLLECTORS}

\section{ABSTRACT}

This article analyses the book Literatura Brasileira em Curso, by Dirce Côrtes Riedel, Carlos Nascimento and Tereza Barbieri (Terezinha de Castro). Taking as reference Walter Benjamin's concepts, 
such as collection, library, miniature, childhood and time assembly, it describes the innovative architecture of the didactic anthology, focusing on the different configurations of textual albums around a number of themes. There are procedures that encourage multiple reading experiences, pointing to contemporary modes of perceiving the emergency of a Brazilian literature, being very innovative in relation to historical practices of classification and text ordering. KEYWORDS: Brazilian literature; collection; reading.

\section{REFERÊNCIAS}

AGAMBEN, Giorgio. Infância e História. Destruição da experiência e origem da história. Trad. Henrique Burigo. Belo Horizonte: Editora UFMG, 2005.

BENJAMIN, Walter. Eduard Fuchs, colecionador e historiador. In: O anjo da história. Walter Benjamin. Org. e Trad. João Barrento. Belo Horizonte: Autêntica, 2013.

. Rua de Mão Única. Obras Escolhidas Vol.II. Trad. Rubens R. Torres Filho e José Carlos M. Barbosa. São Paulo: Brasiliense, 1987.

MISSAC, Pierre. Passagens de Walter Benjamin. São Paulo: Iluminuras, 1998. RIEDEL et alii. Literatura Brasileira em Curso. 4a . Ed.. Rio de Janeiro: Bloch Editores, 1971.

WAIZBORT, Leopoldo. Eric Auerbach sociólogo. In: São Paulo: Tempo Social, vol. 16, no. 1, junho 2004. Fonte: http://dx.doi.org/10.1590/S010320702004000100004 , Acesso em 3 de junho de 2016.

Recebido em: 14 de outubro de 2016

Aceito em: 26 de outubro de 2016 